\title{
Funções discursivas dos marcadores olhe, olha e repare na fala sergipana
}

\author{
Discursive functions of markers olhe, olha and repare in Sergipe speech
}

\author{
Rebeca Rodrigues de Santana* \\ Universidade Federal de Sergipe \\ São Cristóvão, Sergipe, Brasil
}

Resumo: Os marcadores discursivos são itens que exercem um importante papel comunicativo, articulando simultaneamente valores distintos: de caráter textual, ao estabelecer ligações coesivas entre partes do texto e de caráter interpessoal, ao manter a interação entre os interlocutores e auxiliar no planejamento da fala (MARCUSCHI, 1989). O presente trabalho tem como objetivo geral descrever as funções dos marcadores discursivos olhe, olha, veja e repare em um corpus sergipano, e como objetivos específicos: identificar todas as ocorrências dos referidos marcadores na amostra Redes Sociais de Informantes Universitários de Itabaiana/SE (ARAÚJO; SANTOS; FREITAG, 2014); analisar tais ocorrências quanto às funções desempenhadas, e contribuir com a descrição e sistematização de tal categoria. Para tanto, selecionou-se 24 interações conduzidas da amostra Redes Sociais de Informantes Universitários de Itabaiana/SE (ARAÚJO; SANTOS; FREITAG, 2014), pertencente ao Banco de Dados Falares Sergipanos (FREITAG, 2013, 2017). Selecionadas as interações, realizou-se a extração de todas as ocorrências dos marcadores propostos para análise. Em seguida, tais ocorrências foram analisadas quanto ao seu valor funcional nos contextos empregados, sendo as ocorrências de olhe e olha também ouvidas para constatar usos vocalizados (ói e óia). Por fim, os dados obtidos foram submetidos à análise estatística descritiva. Os resultados alcançados nesse estudo podem contribuir com os trabalhos descritivos de marcadores discursivos, mais especificamente de chamada de atenção do ouvinte, e também com estudos acerca da fala sergipana, uma vez que o corpus utilizado é uma amostra de fala de uma comunidade universitária do estado de Sergipe.

Palavras-chave: Marcadores discursivos de chamada de atenção. Formas. Funções.

Abstract: Discursive markers are items that play an important communicative role, articulating simultaneously different values: textual character, establishing cohesive links between parts of the text and interpersonal character, maintaining the interaction between the interlocutors and assisting in the planning of speech (MARCUSCHI, 1989). The present work aims at describing the functions of the discursive markers olhe, olha, veja and repare a Sergipe's corpus, and as specific objectives: to identify all occurrences of these markers in the sample Social Networks of University Informers of Itabaiana / SE (ARAÚJO; SANTOS; FREITAG, 2014). analyze such occurrences as to the functions performed, and contribute to the description and systematization of such category. In order to do so, we selected 24 interactions conducted from the sample Social Networks of University Informers of Itabaiana / SE (ARAÚJO; SANTOS; FREITAG, 2014), belonging to the Falares Sergipanos Database (FREITAG, 2013, 2017). Once the interactions were selected and extracted from all occurrences of the proposed markers for analysis. Then, such occurrences were analyzed for their functional value in the contexts used, with occurrences of olhe and olha also heard to verify vocalized uses (ói and óia). Finally, the data obtained were submitted to statistical descriptive analysis. The results obtained in this study may contribute to the descriptive works of discourse markers, more specifically the listener's attention, as well as studies about Sergipe`s speech, since the corpus used is a speech sample from a university community in the state of Sergipe.

Keywords: Discourse markers. Forms. Functions.

* Mestranda em Letras pela Universidade Federal de Sergipe. Bolsista CNPq e membro do Grupo de Estudos em Linguagem Interação e Sociedade - GELINS. E-mail: rebeca.rodrigues.17@gmail.com 


\section{INTRODUÇÃO}

Os marcadores discursivos são elementos presentes na conversação, que, segundo Marcuschi (2003, p.62), não acrescentam novas informações para o desenvolvimento do assunto, "mas situam-no no contexto geral, particular ou pessoal da conversação". Ainda conforme o referido autor, os marcadores discursivos (MD), por ele chamados de marcadores conversacionais, são divididos, dentre outros critérios, de acordo com sua fonte de produção, podendo ser sinais do falante que orientam o ouvinte ("olha", "veja", "bom", "como vê" etc.), ou sinais do ouvinte que orientam o falante ("ahã", "mesmo?", "duvido", "de fato" etc.).

O objeto deste trabalho são marcadores discursivos utilizados pelo falante para chamar a atenção do ouvinte para o seu texto (ROST, 2002), o que constitui um processo de focalização de informações. Tal focalização é definida por Freitag (2007) como uma função de natureza interpessoal e também de natureza textual, uma vez que o falante utiliza de itens de natureza discursiva (os MD) para chamar a atenção para determinado trecho ou elemento textual com finalidades cognitivo-pragmáticas como, por exemplo, acionar a informação na memória do interlocutor, verificar a compreensão do que foi dito, destacar certas informações etc., como também tais requisitos de apoio discursivo podem ser utilizados para destacar itens e trechos do texto com o intuito de organizá-lo, por meio da ordenação de segmentos textuais.

Os marcadores com tal função focalizadora analisados neste trabalho são os itens lexicais "veja", "repare", "olha", "olhe" e as formas vocalizadas "óia", "ói”, todos inicialmente pertencentes à classe gramatical dos verbos e que passam por um processo de perda de seu significado de percepção física e adesão de uma função de percepção cognitiva, como destacam Gorski et alii (2002), e Rost (2002,) a respeito de "olha" e "veja", e que podemos afirmar que ocorre com os demais aqui propostos.

A relevância desse estudo está em contribuir para a descrição dessa categoria muito importante na conversação e cada vez mais presente nos textos tanto falados quanto escritos, mas que ainda não está prevista nas gramáticas normativas, o que, segundo Freitag (2007, p. 23), "torna-os estigmatizados, sendo muitas vezes considerados um 'vício de linguagem' ou um 'cacoete linguístico"'. Assim, esse trabalho pode contribuir com a sistematização da classe dos marcadores discursivos e com o fortalecimento da ideia de que eles são elementos que, assim como outros prescritos nas gramáticas, têm a sua regularidade e ao invés de serem considerados como vícios podem ser vistos como recursos utilizados pelo falante para organizar o seu texto, ou para estabelecer uma relação com seu interlocutor, fortalecendo assim o caráter interacional da conversação.

O presente trabalho tem como objetivo geral descrever as funções dos marcadores discursivos olhe, olha, veja e repare em um corpus sergipano, e como objetivos específicos identificar todas as ocorrências dos referidos marcadores na amostra Redes Sociais de Informantes Universitários de Itabaiana/SE (ARAÚJO; SANTOS; FREITAG, 2014) e analisar tais ocorrências quanto às funções desempenhadas, e contribuir com a descrição e sistematização de tal categoria. Este estudo alinha-se aos demais estudos descritivos sobre marcadores discursivos na fala sergipana que vem sendo desenvolvidos no âmbito do Grupo de Estudos em Linguagem, 
Interação e Sociedade, a exemplo de Freitag (2007; 2008, 2009, 2010) e Freitag, Silva e Evangelista (2017).

Para realizar a análise, foram selecionadas 24 interações conduzidas da amostra Redes Sociais de Informantes Universitários de Itabaiana/SE (ARAÚJO; SANTOS; FREITAG, 2014)1, pertencente ao Banco de Dados Falares Sergipanos (FREITAG, 2013, 2017). Selecionadas as interações, realizou-se a extração de todas as ocorrências de olhe, olha, veja e repare seguidas do seu contexto linguístico anterior e posterior. Em seguida, tais ocorrências foram analisadas quanto ao seu valor funcional nos contextos empregados, sendo as ocorrências de olhe e olha também ouvidas para constatar usos vocalizados (ói e óia). Por fim, os dados obtidos foram submetidos à análise estatística descritiva.

Esse trabalho está dividido em cinco sessões. Na primeira, é feita uma introdução por meio da apresentação do objeto de estudo, os marcadores discursivos de chamada de atenção do ouvinte; dos objetivos gerais e específicos da pesquisa; justificativa e procedimentos metodológicos realizados para o alcance de tais objetivos. $\mathrm{Na}$ segunda seção, apresenta-se a fundamentação teórica que norteia o estudo, trazendo conceitos da categoria dos marcadores discursivos de modo geral e apresentando as funções dos marcadores de chamada de atenção do ouvinte aqui analisados. Na quarta seção, trazemos a análise dos dados e expomos as funções discursivas encontradas para tais marcadores na amostra sergipana utilizada. Por fim, na quinta e última seção, apresentamos as considerações a que chegamos com tal estudo.

\section{MARCADORES DISCURSIVOS}

Embora não previstos na gramática normativa, marcadores discursivos são considerados por muitos autores como itens que exercem funções discursivas importantes na interação. Para Rost (2002, p. 37), a motivação para o uso desses elementos é a necessidade do falante em realizar "estratégias interativas no sentido de reorganizar o fluxo do pensamento e, ao mesmo tempo, registrar essa reorganização para o ouvinte”.

Castilho (1989) categoriza os marcadores discursivos em dois tipos: os ideacionais e os interpessoais. Os marcadores pertencentes ao primeiro tipo "são postos em ação pelos falantes para a negociação do tema" e os pertencentes ao segundo, marcadores interpessoais, "propiciam a administração dos turnos conversacionais" (OLIVEIRA, 2012, p. 49), assinalando o início do turno, a tomada do turno, a pretensão em se manter o turno e o encerramento do turno, "entendendo-se por turno qualquer intervenção dos interlocutores (participantes do diálogo), de qualquer extensão” (GALEMBECK, 1999, p. 60). Para Marcuschi (2003), na interação os falantes podem utilizar de três tipos de

\footnotetext{
${ }^{1}$ A amostra utilizada é resultado de uma proposta metodológica de Araújo, Santos, Freitag (2014) na qual a situação conversacional não é mediada por um entrevistador e sim produzida por dois informantes, que, por meio de cartões com tópicos diversificados, conversam entre si por aproximadamente $40 \mathrm{~m}$. Tal amostra é composta por 32 interações conduzidas, realizadas por oito informantes, sendo quatro homens e quatro mulheres, que "formam dois grupos - cada um com duas mulheres e dois homens - em que aqueles que pertencem a um grupo têm relações de proximidade entre si, mas não com os informantes pertencentes ao outro" (ARAÚJO, SANTOS, FREITAG, 2014, p. 104). Assim, o modo como esse corpus foi coletado permite a observação de, além do fator social sexo/gênero, também a do fator pragmático distancia social, pois são interações entre homens e mulheres, próximos e distantes socialmente.
} 
recursos para a realização de marcadores discursivos: os verbais, os não verbais e os suprassegmentais.

Esse trabalho tem como foco marcadores discursivos verbais, que "compreendem um variado conjunto de partículas, palavras, sintagmas, expressões estereotipadas e orações de diversos tipos" (OLIVEIRA, 2012, p. 49) e que, segundo Marcuschi (2003), não contribuem especificamente com novas informações para o desenvolvimento do tópico e sim com a inserção deste na conversação. Os marcadores verbais aqui analisados são os itens olhe, olha, veja e repare.

\section{CARACTERIZAÇÃO DAS FUNÇÕES DE OLHE, OLHA, VEJA E REPARE}

Rost (2002), utilizando dados de fala de informantes das três capitais da região Sul do Brasil (Porto Alegre, Florianópolis e Curitiba), buscou descrever o comportamento dos itens "olha" e "veja" em seus contextos de uso. Assim, identificou em tais itens uma propriedade de chamada da atenção do ouvinte ao contexto discursivo/textual, o que os configura como marcadores discursivos. A autora constatou ainda que o "olha" está em um estágio de mudança mais avançado, segundo ela, em virtude de estar perdendo suas marcas de estatuto verbal e assumindo valores pragmáticos discursivos, enquanto o "veja" parece estar mais preso aos seus traços verbais, estando em um estágio anterior de mudança em relação ao olha.

Em seu estudo, Macedo e Silva (1996) analisaram o "olha", juntamente com os marcadores "ah" e "bom", considerando-o como iniciador de respostas e atuante do nível interacional, o que ocorre, conforme as autoras, nas situações em que se faz necessário preservar a face do interlocutor. Ou seja, elas atribuem ao item um contexto macrofuncional apenas interacional e uma função discursiva específica de atenuação do que é dito.

Para a análise das funções dos marcadores olhe, olha, veja e repare, tomaremos como base as apresentadas por Rost (2002), por serem completas e direcionadas especificamente para os marcadores de chamada de atenção do ouvinte. A autora apresenta tanto o caráter textual, quanto o interpessoal/interacional defendidos por Marcuschi (1989) classificando-os como marcrofunções dentro das quais ela apresenta funções discursivas para os marcadores. No quadro 1, tem-se a macrofunção interacional/interpessoal e as cinco funções discursivas nela presentes, segundo a autora. Já no quadro 2 , tem-se a macrofunção textual e suas quatro funções discursivas presentes nos marcadores de chamada de atenção do ouvinte. 
Macrofunção articuladora interacional "(mais voltada para as atitudes do falante em relação ao texto que ele está produzindo, tendo em vista o interlocutor)" (p. 56):

$\checkmark$ Função de advertência: apresenta advertência, dúvida, ou incredulidade contra o conteúdo expresso pelo falante.

$\checkmark$ Função interjetiva: tem natureza exclamativa, podendo expressar, conforme a entonação, surpresa, alegria ou decepção por parte do falante.

$\checkmark$ Função atenuadora: apresenta "um não comprometimento do falante com as informações, indicando uma posição de incerteza em relação ao que será dito em seguida” (p. 62).

$\checkmark$ Função de planejamento verbal: possibilita ao locutor um breve instante de reflexão para a busca de palavras que melhor expressem as informações que devem ser transmitidas.

$\checkmark$ Função prefaciadora: permite que o falante não desenvolva de imediato o tópico proposto por seu interlocutor.

\section{Quadro 1: Macrofunção interacional e suas funções discursivas Fonte: Elaborado com base em Rost (2002)}

Macrofunção articuladora textual "(mais voltada para a sequenciação do texto, assinalando relações textuais de caráter coesivo)” (p. 56):

$\checkmark$ Função exemplificativa: acrescenta "informações que particularizam e/ou exemplificam o que está sendo dito" (p.69).

$\checkmark$ Função retórica: inicia "uma auto-resposta, isto é, o falante formula uma pergunta (retórica) que ele mesmo responde na sequência discursiva" (p. 68).

$\checkmark$ Função causal: "com a justaposição dos itens linguísticos porque olhe, o falante parece encadear coesivamente o resultado de uma série de argumentos que estava apresentando, ao mesmo tempo em que solicita a atenção do ouvinte para a situação descrita" (p. 6).

$\checkmark$ Função concessiva: ocorre com "a expressão e olhe lá como uma espécie de concessão, além da qual o informante não pretende ceder sua opinião a respeito do que diz" (p. 71).

\section{Quadro 2: Macrofunção textual e suas funções discursivas}

Fonte: Elaborado com base em Rost (2002)

Observa-se que a autora considera as funções de advertência, interjetiva, atenuadora, de planejamento verbal e prefaciadora como interacionais, ou seja, como recursos utilizados pelo falante para estabelecer uma relação com seu interlocutor, e as funções exemplificativa, retórica, causal e concessiva como textuais, como mais voltadas para o texto do falante.

\section{PRODUTIVIDADE DAS FUNÇÕES DE OLHE, OLHA, VEJA E REPARE NA FALA SERGIPANA}

Como resultados, foram obtidas 58 ocorrências das formas analisadas funcionando como marcadores discursivos, sendo apenas 2 de repare, 3 de olha vocalizado ['oja], nenhuma de veja e 53 de olhe também vocalizado ['oj]. Em tais ocorrências foram identificadas 6 funções discursivas com as quais tais marcadores foram utilizados: função de advertência, atenuadora, exemplificativa, interjetiva, de planejamento verbal e prefaciadora, e com exceção da exemplificativa, todas as encontradas estão inseridas na macrofunção interacional. 


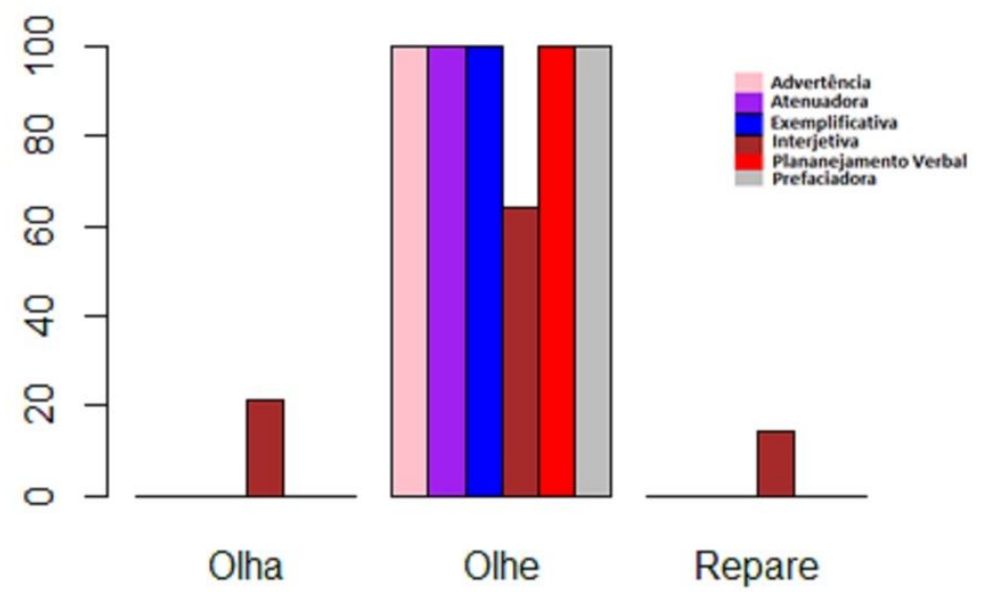

Figura 1: Distribuição das funções discursivas das formas encontradas

A figura 1 apresenta a distribuição das funções quanto às formas encontradas no corpus, e por meio dela pode-se perceber que as poucas ocorrências de olha e repare foram utilizadas com função interjetiva, tendo natureza exclamativa, como ocorre nos excertos (1) e (2), nos quais há um caráter exclamativo de desaprovação.

(1) olha que desgraça (LET, F, MF, P)

(2) repare... que sem noção (LET, F, MF, D)

Ainda sobre o resultado exposto na figura 1, pode-se perceber que o marcador olhe, o mais produtivo no corpus analisado, foi utilizado com todas as 6 funções identificadas: função de advertência, atenuadora, exemplificativa, interjetiva, de planejamento verbal e prefaciadora, e os excertos (3) a (8) exemplificam tais funções respectivamente.

(3) Eu disse "olhe minha filha você decida ou você me coloca logo ou eu vou embora e você devolve o men dinheiro porque eu sou de fora en tenho hora pra ir pra casa" (LET, $F, M F, P)$.

Em (3), temos o marcador sendo utilizado em uma fala reportada, uma citação direta, na qual a informante o empregou para advertir seu interlocutor sobre sua partida, caso sua solicitação não fosse atendida. Trata-se de uma situação na qual a informante fala para seu interactante sobre um momento de espera bastante demorado em uma clínica médica.

(4) Olhe sinceramente eu não se-não consigo imaginar... porque assim eu com com hoje em dia as coisa a uma uma adolescente chegar pra mãe e falar desses assuntos ou a mãe mesmo puxar é uma coisa mais... de costume que é uma coisa mais corriqueira até porque a midia já coloca isso tanto né? (D AM, F, FF, D). 
Já em (4), temos o olhe sendo utilizado para atenuar a abordagem de um assunto bastante impositivo que é falar com os pais sobre relações sexuais.

(111) não e pedagogo ainda eu eu não sei eu digo todo dia a minha namorada... "meu Deus eu não sei como você vai ter paciência" assim eu não gosto muito de criança não são poucas crianças que eu me dou bem... porque tem criança meu Deus olhe eu dei aula de reforço [ o tempo que eu fiquei esperando pra pra entrar na universidade foi quase um ano... que a gente faz fica esperando... esse periodo aí minha mãe "não coloque aula de reforço tal" coloquei meu Deus do céu eu não tinha paciência não (DIE, M, MF, D)

Em (5), o informante faz uso de tal marcador para inserir um exemplo que reforça a ideia apresentada anteriormente, por meio do olhe ele insere um relato sobre uma experiência de dar aula de reforço que confirma sua afirmação de que não tem habilidades para lidar com crianças.

(6) Olhe sim e e e o carinho da mãe cadê cadê então não significa nada não é? (D AV, $M, M M, P)$

Já em (6), temos o marcador sendo utilizado de forma exclamativa, como uma desaprovação, em um contexto em que o informante reprova exclamativamente uma afirmação de que ele teria sorte porque apesar de ter sido abandonado pela mãe, teve uma avó para criá-lo. Tal caráter exclamativo é confirmado pela escuta do áudio, pois o marcador apresenta uma altura em relação aos demais segmentos.

(7) Tinha um monte de... olhe... uma menina me botou no grupo eu disse "olbe me tire desse grupo que eu não gosto dessas coisas eu tô estudando tanto tô quebrando minha cabeça com um monte de coisa" (LET, F, MF, D).

O olhe destacado em (7) tem função de planejamento verbal, pois ocorre em um contexto em que a informante busca palavras para constituir o seu turno, o que pode ser evidenciado, por exemplo, pelo abandono do segmento de fala que inicia o turno "Tinha um monte de...", como também pela presença de pausa antes e depois do marcador.

(8) na aula assim olhe eu já tô no último estágio... a gente passou uma atividade... e o aluno veio com uma cópia fiel... de um artigo... eu digo não primeiro que... ele não tem orientação de como que faz essa... formatação e tal cê percebe... de acordo com as outras atividades que eles tinham feito... a concordância do texto... era totalmente diferente eu disse isso aqui foi uma cópia fiel da internet (DIE, $M, M F, D$ ).

E, em (8), tem-se o marcador sendo utilizado com função prefaciadora, pois é perguntado ao informante o que ele pensa a respeito do plágio e ele apresenta todo 
um relato inicial de uma situação envolvendo o plágio, sem fazer o que é proposto por seu interactante que é opinar sobre o assunto.

A análise evidencia que o marcador olhe, em sua forma vocalizada (ói), é bastante utilizado como marcador discursivo pelos informantes da amostra Redes Sociais de Informantes Universitários de Itabaiana/SE (ARAÚJO; SANTOS; FREITAG, 2014), uma vez que $92 \%$ das ocorrências foram de tal marcador; além deste uso, as funções discursivas desempenhadas por tal item também foram bastante diversificadas, destacando-se a maior ocorrência na macrofunção interacional.

A seguir, são elencadas as funções discursivas encontradas para os marcadores em análise e são apresentados mais excertos do corpus que as exemplificam.

\subsection{FUNÇÃO DE ADVERTÊNCIA}

A função de advertência foi uma das duas funções mais produtivas nos marcadores analisados, tendo apresentado 15 ocorrências equivalentes a um percentual de $26 \%$ do total das funções. Os excertos (9), (10) e (11) trazem mais exemplos dessa função na qual o marcador é utilizado para advertir sobre algo.

(9) o médico diz. "olhe pegue o original" não é? agora remédio de prefeitura ai é que o povo dizia "peguei ganbei na pre-ganbei no hospital... público não presta pra nada" gente que vinha interior mas nada a ver (LET, F, MF, D).

(10) não a primeira vez que ele procurou... o Médico só disse "olhe você vai ter que se cuidar ou então senão... pode acontecer o o pior viu?" aí pronto ai ele se preocupou logo... deu aquela depressão danada né? se isolou do mundo... faleceu (WAG, $M, M M, P$ ).

(11) mas caso você um dia... presenciar... qua- qual será assim sua atitude? cê vai chegar pra esse menino dizer "olhe não faça isso" ou cê vai (WAG, M, MF, D).

Nesses três exemplos, assim como na maioria das ocorrências da referida função, o marcador foi utilizado em citações diretas, assim, a advertência era feita a um indivíduo exterior à situação conversacional e não ao interlocutor. Em (9), podese perceber o olhe sendo atribuído à fala de médicos que alertam os pacientes a comprarem remédios originais, em lugar dos genéricos. Em (10), sendo atribuído também à fala de um médico, nesse caso um específico, o que atendeu o pai do falante, orientando-o a cuidar da saúde para evitar o que acabou acontecendo, o seu falecimento. E, em (11), tem-se o marcador sendo utilizado em uma advertência hipotética que o falante indaga a sua interlocutora se ela faria caso presenciasse um garoto furtando algo.

\subsection{FUNÇÃO INTERJETIVA}

A outra função mais produtiva, também com 15 ocorrências e percentual de $26 \%$, foi a interjetiva, que ocorreu em contextos em que os informantes fazem uso 
do marcador com uma entonação própria que lhe confere um caráter relacionado à emoção, excertos (12), (13) e (14).

(12) olhe essas coisas só acontece quando eu não venho no dia... quando eu não venho acontece um negócio desse ( $\mathrm{D} A V, M, M F, P)$.

(13) tinha mais mulheres dentro de casa? ave Maria... olhe TPM de mulher... é TPM de mulher que redundância... só mulher tem TPM né? (DIE, M, MF, P).

(14) conbece "olhe você é amiga de fulano" "conbece fulano?"... às vezes fica mais amiga da pessoa do que da outra que já conbecia né? (...) (LET, F, FF, P).

Em (12), ao se referir a um fato de violência contra uma estudante da universidade da qual o informante faz parte, ele faz uso do marcador de forma exclamativa, demonstrando indignação ao mesmo tempo em que dá entender que se estivesse presente teria feito algo a respeito. Com a mesma função, em (13), o olhe, assim como a expressão com caráter de interjeição que o precede "ave Maria", é utilizado para demonstrar certo desagrado com relação ao período pré-menstrual das mulheres. E em (14), o marcador é utilizado em um discurso direto para indicar alegria, empolgação, em um contexto em que a informante reporta-se à situação de descobrir uma amizade em comum e fazer uma nova amizade a partir disso.

\subsection{FUNÇÃO DE PLANEJAMENTO VERBAL}

Outra função que está dentre as mais produtivas no uso dos marcadores é a de planejamento verbal com 10 ocorrências, o que equivale a um percentual de $17 \%$ para essa função utilizada em situações de planejamento de fala, excertos (15) a (17).

(15) já é já era a última a pazinha assim de olhe por cima do caixão (DAV, M, MF, P).

Em (15), pode-se notar que o informante usa o marcador ao fazer uma correção da preposição "de" por uma mais adequada para a sentença produzida, a preposição "por". Outra possibilidade é de ter ocorrido um planejamento verbal por meio de abandono de algo a ser dito sobre o termo "pazinha" (pazinha de algo), seguido de um acréscimo de onde essa pazinha seria despejada. Cabe destacar que o contexto no qual esse excerto está inserido é de comentário metafórico sobre a situação financeira da parceira conversacional que afirma que além de seus gastos diários fará sua formatura e será madrinha de um casamento no mesmo mês.

(16) uma mulher... tem uma mulher que ficou doida sabe? ai ela é bem morena bem morena... ai todo mundo que chegava na casa dela ela dizia bem as sim olhe ela dizia bem assim "olhe meu marido arranjou uma rapariga mas é feia venha ver como é preta" mostrava a foto dela mesma... no espelho era bem preta e era ela (quando) ficou doida (LET, F, FF, P). 
Em (16), a informante, ao fazer um relato, utiliza o marcador em destaque também em uma situação em que está planejando a sua fala, o que pode ser evidenciado pela presença da repetição do segmento "ela dizia bem assim", para então chegar à produção do restante da fala que informa o que é fora dito pela pessoa reportada.

(17) é pe-é pensão olhe pensão... bater em mulher ( $W A G, M, M M, D)$.

Já em (16), o uso do marcador para planejamento da fala ocorre em uma situação em que o informante, ao falar de impunidade no Brasil, tenta listar as três situações que, segundo ele, podem levar um indivíduo a ser preso no país. O planejamento pode ser observado nesse caso por múltiplos aspectos, como, por exemplo, pelo truncamento que ocorre antes de "pensão"; pela repetição desse termo após o uso do marcador; pela ocorrência de pausa e até pelo fato de o informante não ter apresentado a terceira situação, o que dá uma impressão de que o tempo todo ele tenta lembrar quais são elas.

\subsection{FUNÇÃO ATENUADORA}

Outra função dentre as identificadas no uso dos marcadores analisados foi a atenuadora com 9 ocorrências, o que equivale a 16\% do total dos 58 usos desses marcadores de chamada de atenção do ouvinte no corpus. Os excertos (18) a (20) exemplificam tal função.

(18) olhe eu acho assim que o racismo vem dos negros mesmo porque tipo assim a gente tá numa fila... ne uma fila não ne um na faculdade... aí vamos apresentar "fulana primeiro" a Professora chamou ela não é nem porque ela é negra foi porque não pensou em ninguém chamou ela... mas a menina já pensa só porque eu sou negra acho que o racismo mais é questão da pessoa mesmo eu tenho uma Professora que é negra (LET, F, $M F, D)$.

A maioria das ocorrências do marcador na função atenuadora deu-se em contextos em que os assuntos tratados eram mais impositivos, principalmente em casos em que se pedia a opinião do falante sobre um assunto considerado tabu socialmente, o que pode ser observado nos presentes excertos. Em (18), a informante utiliza o marcador no início do seu turno como uma forma de atenuar sua opinião sobre o tópico racismo.

(19) não gosto muito dessas coisas não... mas assim também conbeço os conheço alguns que são... desde que haja com respeito a si mesmo e aos outros tranquilo tá aqui de boa olhe não ligo de... de tá assim desde que haja o respeito (DIE, M, MF, D) 
Em (19), o mesmo é feito pelo informante ao responder a uma pergunta sobre o que ele acha das pessoas homossexuais e se ele tem algum problema em estar próximo dessas pessoas, o marcador ocorre justamente quando o informante vai dizer que não tem oposição em estar em presença de homossexuais, mas apresenta uma condição que é o respeito.

(20) não meu amigo pulava a cerca é diferente... "olhe minha velha fique ai e eu vou aqui resolver uma umas coisas vou trabalhar agora"... ai en ia gastar o dinhei ro dela com outra né? (WAG, M, MM, D).

Já em (20), ocorre algo um pouco diferente dos dois excertos anteriores, o informante tem uma posição de utilizar o marcador para atenuar não algo que é dito ao seu interlocutor, mas a alguém exterior à conversação. Ao responder a uma pergunta sobre a possibilidade de ele se casar com uma pessoa mais velha por dinheiro, ele afirma para o seu interlocutor homem, sem atenuar sua fala, que casaria, mas que a trairia. O marcador com função de atenuação ocorre quando o informante produz um discurso direto sobre o que ele diria para a mulher ao sair de casa para traí-la, utilizando o olhe para atenuar o aviso da saída, assim como mentindo sobre o local para onde iria.

\subsection{FUNÇÃO EXEMPLIFICATIVA}

Outra função presente nos marcadores analisados foi a exemplificativa com 6 ocorrências equivalentes a $10 \%$ do percentual para essa função na qual o informante utiliza o marcador para exemplificar o que está sendo dito, excertos (21) a (23).

(21) não tem como fazer tem gente que... ensina os filhos também... tipo olhe tem uma colega minha [ (LET, F, FF, P).

(22) olhe quer ver eu azedar eu azedo em banco quando a gente tá naquela fila e uma pessoa tá lá... vem dez. mil pessoa "pague isso pra mim pague isso pra mim" eu chego lá eu disse "olhe minha filha é a minha vez porque você já pagou sua conta eu sei que você já pagou sua conta paga de um monte de gente eu tenho o que fazer" eu já disse e digo (LET, F, MF, D).

(23) bom a minha é uma coisa... ela é bem danadinha assim... eu xingo faço tudo... agora não dou tudo a ela não sabe? tipo ela vê um negócio ali ela quer... eu converso com ela que não pode... ela se cala... agora eu já presenciei... meu primo quando era menor... a gente tava aqui... fazendo compras eu minha mãe minha tia e ele... ele queria um negócio... a mãe não deu ele se esperneou jogou no chão... olhe fez a maior feiura quando chegou em casa ele levou uma surra... ai eu vi aí minha mãe disse "tá vendo... não faça isso não porque senão cê apanha..." aí eu acho que eu nunca fir. isso não... mas é feio né? (LET, $F, F F, D)$. 
A maior parte das ocorrências dessa função deu-se em situações em que o informante utilizou uma narrativa para exemplificar o que estava sendo dito tanto por ele quanto por seu interlocutor. Em (21), quando perguntado à informante sobre o que ela acha de pessoas que distinguem outras pela cor da pela, ela utiliza o marcador para inserir um exemplo sobre o caso de pessoas que ensinam isso também aos seus filhos. O exemplo não é finalizado nesse turno porque ela é interrompida por sua interlocutora, como indica a presença do colchete. Em (22), a informante utiliza o marcador, quando perguntada sobre pessoas que não respeitam ordem/fila de atendimento, para exemplificar algo que diz respeito ao assunto e que a deixa irritada que é o de pessoas que não respeitam a ordem no atendimento em bancos. E em (23), ao ser questionada sobre o tópico comportamento de crianças, utiliza o marcador em uma exemplificação sobre um mau comportamento realizado por um primo seu quando mais novo.

\subsection{FUNÇÃO PREFACIADORA}

A função prefaciadora foi a menos recorrente no corpus com apenas três ocorrências, excertos (8), (24) e (25), equivalentes a 5\% do percentual de uso dos marcadores de chamada de atenção do ouvinte analisados para essa função na qual o informante utiliza o marcador para não desenvolver o tópico de imediato.

(24) e antigamente também os remédio tá certo tem uns remédio hoje que... queira ou não queira faz. o que... cura o que antigamente não fazia curava né? mas é... é aquela questão também porque você vê olhe... esse pessoal idoso nossos avós mesmo será que hoje a idade nós chega a idade deles? pode até chegar agora é difícil né? é difícil... e hoje também en culpo além da da alimentação que nós tem também os remédios é... né muita coisa boa não (WAG, M, MM, P).

(25) olhe tem gente que hoje em dia ainda valoriza a pessoa pela cor... o quê você acha dessas pessoas? (LET, F, FF, P).

Em (24), ao responder a uma pergunta sobre sua opinião a respeito de remédios genéricos, o informante não desenvolve especificamente esse tópico, ele faz uma explanação sobre remédios de um modo mais geral e utiliza o marcador nessa prefaciação. E em (25), o marcador é utilizado como prefaciador de uma pergunta sobre racismo, pois a informante opta por, ao invés de fazê-la de forma mais direta, apresentar uma afirmação inicial sobre a existência de pessoas racistas.

\section{CONSIDERAÇÕES FINAIS}

Neste trabalhos foram apresentadas e discutidas as funções desempenhadas pelos marcadores veja, olha, repare e olhe nas 24 interações conduzidas selecionadas da amostra Redes Sociais de Informantes Universitários de Itabaiana/SE (ARAÚJO; SANTOS; FREITAG, 2014), com exceção do veja por não ter ocorrido nenhum uso de 
tal forma como marcador discursivo, o que pode estar relacionado tanto à falta de produtividade desse item como marcador na comunidade analisada, quanto ao que Rost (2002) afirma sobre seu estado menos avançado da mudança que envolve a perda de seus traços verbais para a aquisição de funções discursivas.

Quanto aos outros marcadores propostos para analise, foi possível perceber que olha (óia) e repare também não foram muito produtivos em termos de uso, nem em diversidade funcional, pois ambos ocorreram apenas na função interjetiva, já o olhe (ói) teve uso produtivo e multifuncionalidade, tendo ocorrido em uma macrofunção textual (exemplificativa) e seis macrofunções interacionais (advertência, atenuadora, interjetiva, de planejamento verbal e prefaciadora), o que evidencia uma preferência dos informantes dessa amostra em utilizar o marcador em situações mais voltadas para o seu interlocutor do que ao texto falado produzido.

Cabe ressaltar que os resultados alcançados neste estudo podem contribuir com os trabalhos descritivos de marcadores discursivos, mais especificamente de chamada de atenção do ouvinte, e também com estudos acerca da fala sergipana, uma vez que o corpus utilizado é uma amostra de fala de uma comunidade universitária do estado de Sergipe.

\section{REFERÊNCIAS}

ARAUJO, Andréia Silva; SANTOS, Kelly Carine dos; FREITAG, Raquel Meister Ko. Redes Sociais, Variação Linguística e Polidez: Procedimentos de Coleta de Dado. In FREITAG, Raquel Meister Ko. Freitag (Org.). Metodologia de Coleta e Manipulação de Dados em Sociolinguística. São Paulo: Editora Edgard Blücher, 2014, p.99-116.

CASTILHO, Ataliba Teixeira de. Para o estudo das unidades discursivas no português falado. In: Português culto falado no Brasil. Campinas: Editora da UNICAMP, 1989. p. 249322.

FREITAG, Raquel Meister Ko É. o que?: estratégia de interação ou sequenciação. Estudos Linguísticos, v. 39, n. 1, p. 157-166, 2010.

FREITAG, Raquel Meister Ko Freitag, SILVA, Rosangela Barros, EVANGELISTA, Flávia Regina Santana. Marcadores discursivos interacionais. Diacrítica, n. 31, v. 1, 55-75, 2017.

FREITAG, Raquel Meister Ko. Banco de dados falares sergipanos. In: Working Paper em Linguística, v. 14, p. 156-164, 2013.

FREITAG, Raquel Meister Ko. Estratégias gramaticalizadas de interação na fala e na escrita: marcadores discursivos revisitados. ReVEL, n. 7, v. 13, p.1-10, 2009.

FREITAG, Raquel Meister Ko. Falares sergipanos. In: ATAÍDE, Cleber, et alii (Org.). Gelne 40 anos. São Paulo: Blucher, 2017, p. 119-130.

FREITAG, Raquel Meister Ko. Marcadores discursivos interacionais na fala de Itabaiana/SE. Revista do GELNE, v. 10, n. 1/2, p. 21-32, 2008. 
FREITAG, Raquel Meister Ko. Marcadores Discursivos não são vícios de Linguagem! Revista Interdisciplinar, v. 4, n. 4 - p. 22-43 - Jul/Dez de 2007.

GALEMBECK, Paulo de Tarso. O turno conversacional. In: PRETI, D. (Org.). Análise de textos orais. São Paulo: FFLCHUSP, 1999. p.55-79.

GORSKI, Edair M. et al. Gramaticalização/discursivização de itens de base verbal: funções e formas concorrentes. Estudos Lingüisticos, v. 31, p. 1-10, 2002.

LABOV, William. Padrões Sociolinguísticos. São Paulo: Parábola, 2008, p. 19-62.

MACEDO, A.T.; SILVA, G. M. O. Análise sociolinguística de alguns marcadores conversacionais. In: MACEDO, A.T.; RONCARATI, C.; MOLICA, M. C (org). V ariação e Discurso. Rio de Janeiro: Tempo Brasileiro, 1996.

MARCUSHI, Luiz Antônio. Análise da conversação. 5. ed. São Paulo: Ática, 2003.

ROST, Cláudia A. Olha e veja: multifuncionalidade e variação. 2002. 158 f. Dissertação (Mestrado) - Programa de Pós-Graduação em Linguística, Universidade Federal de Santa Catarina, Florianópolis, 2002.

Recebido em: 15/12/2017

Aprovado em: 26/01/2018

Publicado em: 01/03/2018 